\title{
Al-Sn nanostructured coatings on aluminum surfaces using electrospark alloying and their wear behavior
}

E.V. YURCHENKO, I.D. RUSHIKA, V.I. AGAFII, A.I. DIKUSAR

DOI: 10.30464/jmee.2018.2.2.115

Cite this article as:

Yurchenko E.V., Rushika I.D., Agafii V.I., Dikusar A.I. Al-Sn nanostructured coatings on aluminum surfaces using electrospark alloying and their wear behavior. Journal of Mechanical and Energy Engineering, Vol. 2(42), No. 2, 2018, pp. 115-120.

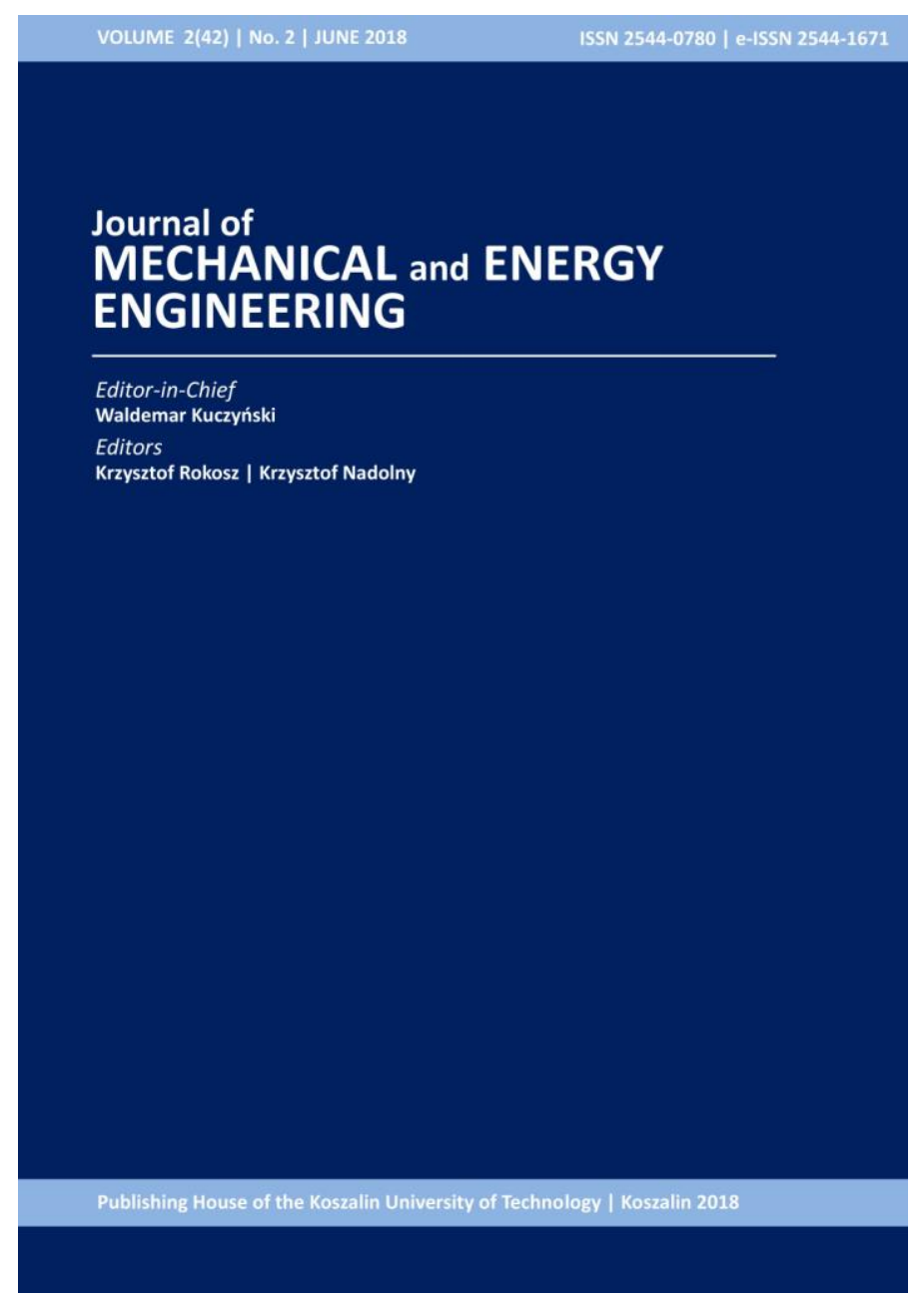

Journal of Mechanical and
Energy Engineering

Website: jmee.tu.koszalin.pl

ISSN (Print): 2544-0780

ISSN (Online): 2544-1671

Volume: 2(42)

Number: 2

Year: 2018

Pages: $115-120$

Article Info:

Received 26 April 2018

Accepted 21 May 2018

\section{Open Access}

This article is distributed under the terms of the Creative Commons Attribution 4.0 (CC BY 4.0) International License (http://creativecommons.org/licenses/by/4.0/), which permits unrestricted use, distribution, and reproduction in any medium, provided you give appropriate credit to the original author(s) and the source, provide a link to the Creative Commons license, and indicate if changes were made. 


\title{
Al-Sn NANOSTRUCTURED COATINGS ON ALUMINUM SURFACES USING ELECTROSPARK ALLOYING AND THEIR WEAR BEHAVIOR
}

\author{
E.V. YURCHENKO ${ }^{1}$, I.D. RUSHIKA ${ }^{1,2}$ \\ V.I. AGAFII ${ }^{1,3}$, A.I. DIKUSAR ${ }^{1,3^{*}}$ \\ ${ }^{1}$ Shevchenko Pridnestrov'e State University, str. 25 Oktyabrya 128, Tiraspol, Republic of Moldova \\ ${ }^{2}$ Technical University of Moldova, bul. Stefan cel Mare 168, MD-2004, Chisinau, Republic of Moldova \\ $3^{3 *}$ Institute of Applied Physics, Academy of Sciences of Moldova, str. Academiei 5, MD-2028, Chisinau, \\ Republic of Moldova, e-mail: dikusar@phys.asm.md
}

(Received 26 April 2018, Accepted 21 May 2018)

\begin{abstract}
At electrspark alloying (ESA) of aluminum surfaces using Al-Sn tool-electrode (TE), nanostructuring of manufactured surfaces take place owing to the formation of $\mathrm{SnO}_{2}$ nanofibers. Examining the tribological properties of these surfaces in a friction couple with a counterbody made of hardened steel showed that the wear of counterbody during the friction in the oil and at dry friction exceeds by an order of magnitude and above it the wear of such surfaces.
\end{abstract}

Keywords: Al-Sn alloy, electrospark alloying, nanostructuring, $\mathrm{SnO}_{2}$ nanofibers, wear resistance

\section{INTRODUCTION}

At electrospark alloying (ESA) take place removal of material from the surface of the anode and its transfer to the cathode in the air. The base of this method of the treatment is local melting of the surface in conditions of electrospark discharges $[1,2]$. It has been show [3, 4], that if the anode is a mechanical mixture of the low-melting component in a refractory matrix (for example, solid solution of $\mathrm{Sn}$ in aluminum matrix), the formation of nano- and microfibers fusible component in the surface layer after treatment take place at ESA. Since ESA carried out in air, the resulting nano- (micro-) fibers of low-melting component are oxides. As a resultat at ESA by TE from Al-Sn alloy in the surface layer after treatment formed of tin oxide nanowires [5].

The methods of obtaining of these surfaces at ESA and the investigation of their durability are presented in our study.

\section{RESULTS AND DISCUSSIONS}

\subsection{Composition and structure of the TE:} physical bases of obtaining the nanowires

Fig. 1 shows a diagram of the state for $\mathrm{Al}-\mathrm{Sn}$ binary system. One can see that at room temperature (up to the tin melting point of $228^{\circ} \mathrm{C}$, the material used as a TE (AlSn20) must be an aluminum matrix with liquid tin metal dispersed in it. The TE is really an aluminum matrix with tin particles with a size of 3-5 $\mu \mathrm{m}$ dispersed in it [3].

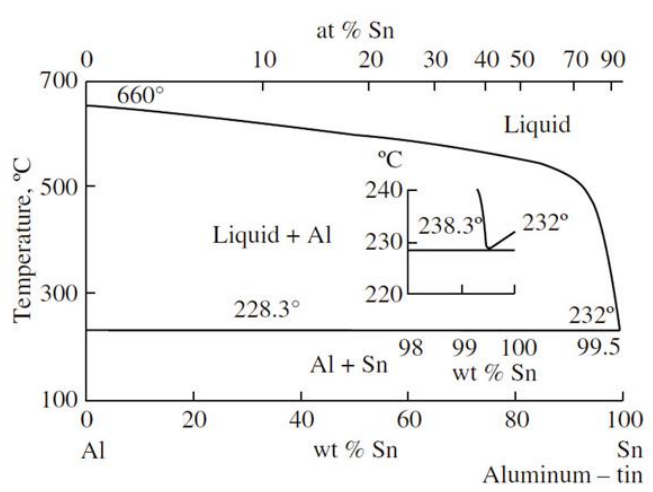

Fig. 1. State diagram for the aluminum-tin system

The cause for the formation of the nanowires at ASE by TE of AlSn alloy is specific character of the AlSn state diagram at temperatures that are higher than the tin melting point $\left(228^{\circ} \mathrm{C}\right)$, but lower than the melting point of aluminum matrix (Fig. 1). In this case, the system represents melted particles of dispersed tin (tin oxide, because treatment take place 
in air) being in a solid matrix of aluminum. The transfer of these particles to the interelectrode gap occurs due to the pondermotive forces that deform the surface of melted drop if the surface tension force of the melt-air system is sufficiently low for the melted particles. As a result, the wires with a diameter of $\sim 1 \mu \mathrm{m}$ (and lower) are formed (Fig. 2). Effects of this kind must be not only for the Al-Sn systems but also for any other systems that, at certain temperatures, are a system of melted particles in a solid matrix, for example the $\mathrm{Al}-\mathrm{Pb}$ system at ASE.

\subsection{Methods of electrosparking machining}

The $8 \mathrm{~mm}$ diameter Al-Sn rods were used as the TE. They were doped with $\mathrm{Cu}(\sim 1$ wt $\%)$ and $\mathrm{Ti}$ $(\sim 1 \mathrm{wt} \%)$. The alloy of the required chemical composition was melted in a graphite crucible with the use of inductor of a high frequency. The melt was filled then into a specially made chill to obtain $\emptyset 8 \times 50 \mathrm{~mm}$ rod that served as the TE.

To obtain an alloy of a preset composition pure aluminum and tin were used. Doping components were introduced as intermediate alloys $(50 \% \mathrm{Al}+50 \%$ $\mathrm{Cu})$ and $(90 \% \mathrm{Al}+10 \% \mathrm{Ti})$.

An ALIER 31 installation served as the power source for the electrospark plating. A peculiarity of this device is that the frequency of the generated pulses is not directly connected with the vibration frequency of the TE but is set independently. The frequency depends on the energy in a pulse. The operation mode 5 of that installation was used in the present study. The frequency of the preset pulses was $\sim 0.1 \mathrm{kHz}$. This was reached using a special regulator of frequency (the energy coefficient).
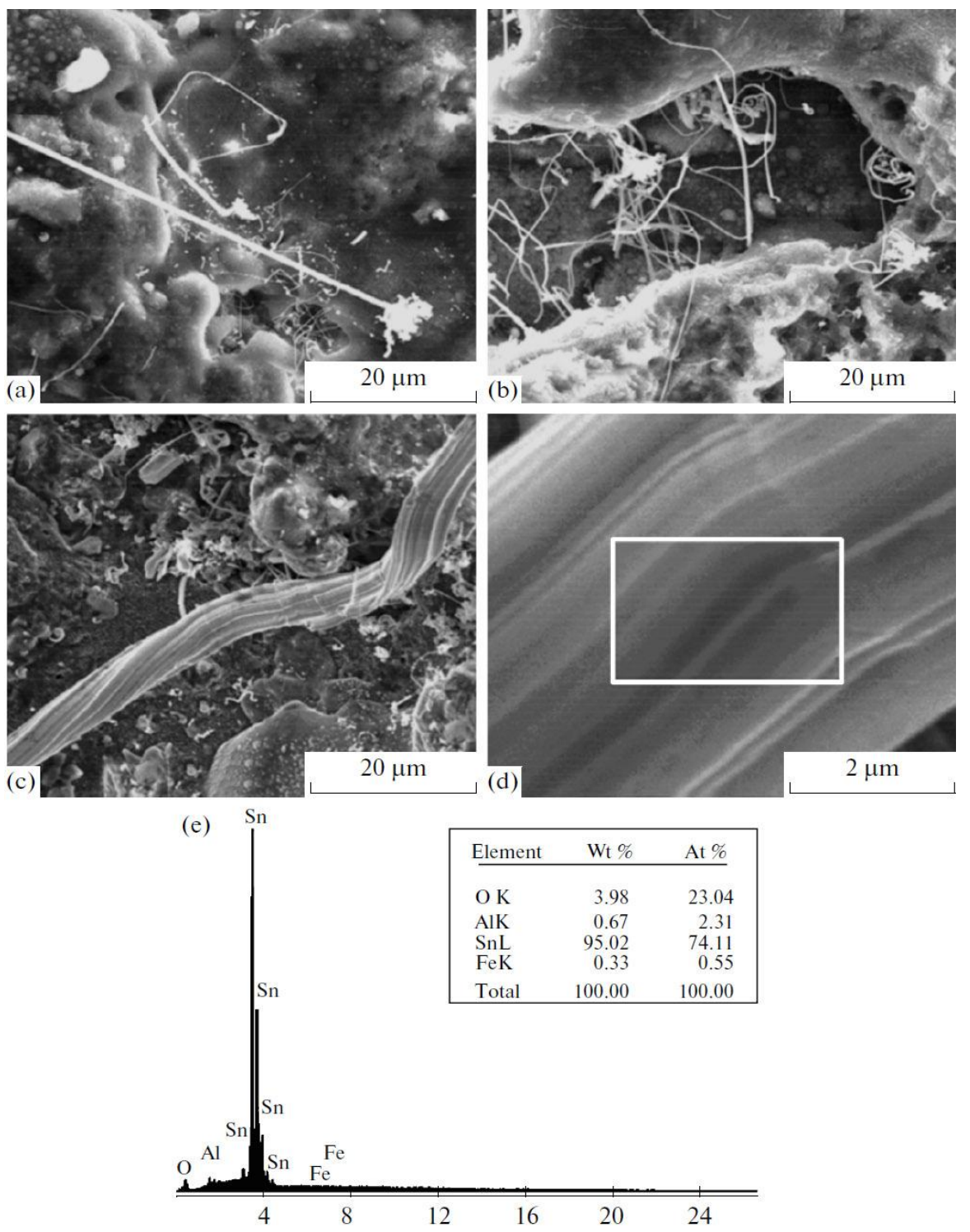

Fig. 2. Morphology of surface layers manufactured using method 1 at TE feed rate of $0.6 \mathrm{~mm} / \mathrm{s}(\mathrm{a}, \mathrm{b}), 1 \mathrm{~mm} / \mathrm{s}(\mathrm{c}, \mathrm{d})$, EDX spectrum and elemental composition of the surface segment (e) marked in Fig. 2d 
In order to produce nanofiber structures under controllable conditions of electrospark plating and determine the optimal modes, an experimental facility was developed for a mechanized coating with a wide range of parameters (Fig. 3). Standard vibrogenerator 2 of ALIER 31 was fixed on a vertical milling head of a milling machine so that it could perform oscillating movements with the adjustable amplitude and frequency in the direction perpendicular to the movement of sliding carriage 5 on which sample 4 was fastened with screws. The amplitude was regulated by means of a special drive cammounted on a vertical shaft of the machine with a possibility of adjusting it in the range of 1 to $10 \mathrm{~mm}$. This made it possible to produce a track of coatings of different widths on the specimen.

The frequency of the transverse oscillations was ensured by the rotation speed (from 20 to $150 \mathrm{rot} / \mathrm{min}$ ) of the vertical shaft. Direct current engine 6 was used as the drive of the shaft.

Specimen 4 was fixed by screws on horizontal sliding carriage 5 of the facility. A special drive 6 (a constant current electric engine plus a reducer) was used to move it along the guide ways. Such device allowed plating of some layers step by step during every forward and backward movement of the carriage. The adjustable power supply allowed controlling the drive speed. Due to this device configuration, the TE fixed on vibrogenerator moves relative to the specimen with a constant preset feed rate. The feed movement of the sliding carriage was regulated in the range of $0.2-6.0 \mathrm{~mm} / \mathrm{s}$.

In addition to the indicated mechanical parameters (the specimen feed rate, amplitude and frequency of the transverse oscillations of the vibrator), the ALIER31 installation itself made it possible to vary the mode of operation, the energy coefficient and amplitude of the electrode vibration.

Thus, the experimental facility provided an opportunity to vary modes by 6 parameters at the automation (hence, with stabilized parameters) coating process.

After the milling cut the specimens surfaces were polished with an abrasive cloth strips to diminish roughness before the ESA coating. After polishing and marking the specimens were weighed on a VLR 200 analytic balance, and after wards they were fixed with two screws on the sliding carriage of the experimental facility. The electrode from the Al-Sn alloy ( 20 mass $\%$ of $\mathrm{Sn}$, manufactured by the above method) was also preliminary weighted and fastened in the vibration generator of ALIER31.

The required operation modes were displayed on the control panel of the experimental facility, i.e., the energy coefficient, amplitude of the generator, mode of operation, and the amplitude and frequency of the transverse oscillations. When the facility was switched,

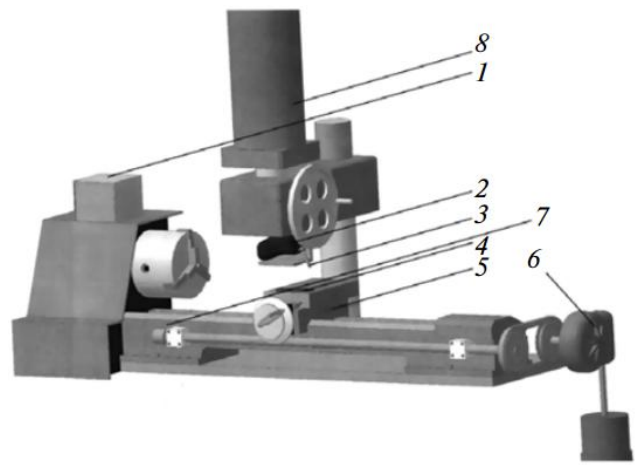

Fig. 3. Scheme of ESA experimental facility for the automation coating. 1 - ALIER 31;2 - vibrogenerator; 3 - electrode; 4 - specimen; 5 - sliding carriage; 6 - regu lated drive of sliding carriage; 7 installation bed; 8 - reg ulated drive of transversal vibrator

on the mechanized coating the process started due to the sliding carriage reciprocal movement. After plating one or two layers, the specimens and electrodes were weighted again to determine the material gain or loss of the specimen or the electrode.Two methods of coating deposition were used.

According to method 1, a constant number of coated layers at every preset speed of the TE movement relative to the specimen were deposited (at this case the effective time of coating deposition depends on the feed rate). Method 2 presupposes the usage of a constant value of the "supplied charge" or an amount of energy introduced into the discharge gap during the deposition process (in the present study it is refered to as the method "with constant energy amount"). Using method 2, the number of the plated coatings was increased proportionally to an increase in the TE feed rate.

According to method 1, the constant number of the deposited layers were 4 at various TE feed rates with respect to the specimen; the rates varied in the range of $0.3-2.0 \mathrm{~mm} / \mathrm{s}$ : the TE traveled as many as four times with a preset rate along the entire surface under treatment. In the case of deposition by method 2 four layers were deposited (the TE traveled 4 times along the surface) at the speed of $0.5 \mathrm{~mm} / \mathrm{s}$ of the TE displacement and 16 layers at the feed rate of $2 \mathrm{~mm} / \mathrm{s}$; 8 and 12 layers were deposited at the feed rates of 1.0 and $1.5 \mathrm{~mm} / \mathrm{s}$, respectively.

The results of the weighting were used to determine a specific deposition rate $G$ in $\mathrm{mg} /\left(\mathrm{s} \cdot \mathrm{cm}^{2}\right)$ which, depending on conditions, could be either of a positive or of a negative value; in the latter case, the weight of the specimen after the treatment did not increase but rather decreased. The total time of the treatment and the overall area of the modified surface were taken into account to calculate $G$.

The surfaces of the specimens (prior to and after the treatment) were also examined in order to study 
the morphology and the elemental composition using the scanning electron microscopy - a TESCAN scanning microscope with an INCA Energy EDX (Oxford, Great Britain) attachment for the surface elemental analysis.

To determine the surfaces roughness of the specimens (parameter $R a$ ) and their profiles a Surtonic profilograph-profilometer (Taylor Hobson, GB) was used. The measurements were performed at 12 points along the preset length of tracing of $12.5 \mathrm{~mm}$. The average value of $R a$ and a standard deviation were cal culated based on the obtained measurements. The wear tests were carried out using a friction machine with a reciprocal movement (from the Institute of Applied Physics of the Academy of Sciences of Moldova [2, 5]).

In the first variant of treatment (by hand) was obtained only the weight gain of the specimens. In the second variant of specimen treatment used in the study the number of the TE passes along the treated surface were changed at changing the TE feed rate.

Fig. 4 demonstrates the dependences of a specific deposition rates on the TE feet rate across the surface under treatment. It is seen that at different methods of treatment (with a constant number of layers (method 1) and with constant energy amount (method 2) a specific deposition rate remains to be constant in a certain interval of the TE feed rates.

A transition from method 1 to method 2 of the treatment changes only the "critical" value of the TE feed rate, when we can notice the transation from ESA mode which yields the weight gain of the specimen under treatment (let us call it mode I) to the mode where the mass loss occurs after ESA (we shall refer to it the method of "sparking" or mode II, which means modification of the surface under sparks action without noticeable weight gain) - Fig. 4 .

\subsection{Wear resistance of the coatings after ESA by the Al-Sn alloy. ESA by hand}

The study of the mechanical properties of the surfaces developed with the formation of nanofibers from low-melting component was carried out using friction machin (see before). Counterbody was plate from the hardened steel St.45 with microhardness 650 $\pm 50 \mathrm{kgf} / \mathrm{mm}^{2}$. The couterbody performed a reciprocal movement relatively the specimen under study at a 45 double movements a minute. The length of the working surface that contacted the counterbody was $48 \mathrm{~mm}$. The weight loss measurements were performed both for the counterbody $\left(\Delta U^{c b}\right)$ and for the tested specimens $(\Delta U)$. A degree of the wear was estimated both in the absolute and in the relative $\left(\Delta U^{c b} / \Delta U=K\right)$ values. The testing was both at dry friction and lubricated friction. Fig. 5 demonstrates relative wear of the surfaces, obtained ESA by hand at dry friction.

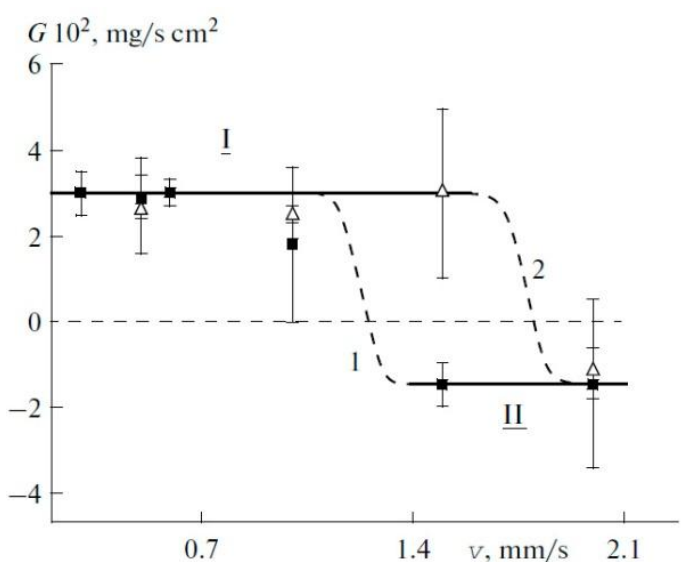

Fig. 4. Dependence of ESA deposition rate on TE feed rate for specimens obtained by method 1 (constant number of layers) and method 2 (constant amount of energy): region I - mode with mass gain; region II mode with mass loss

Test experiments were performed in two stages. At the first stage grinding-in of the counterbody and the test surface was performed. It was carried out during ten hours of testing with load changing from 2 to $9 \mathrm{~kg}$ (a contact area of tested surface with the counterbody was $9 \mathrm{~mm}^{2}$, and the overall area of the treated surface against which the counterbody was performing a reciprocal movements was $165 \mathrm{~mm}^{2}$ ).

The grinding-in at the initial and final loads was done during two hours and the intrmediate loads during one hour. At the second stage, the main test experiments were performed at $9 \mathrm{~kg}$ load during $20 \mathrm{~h}$. Before and after every test the surface roughness ( $R a$

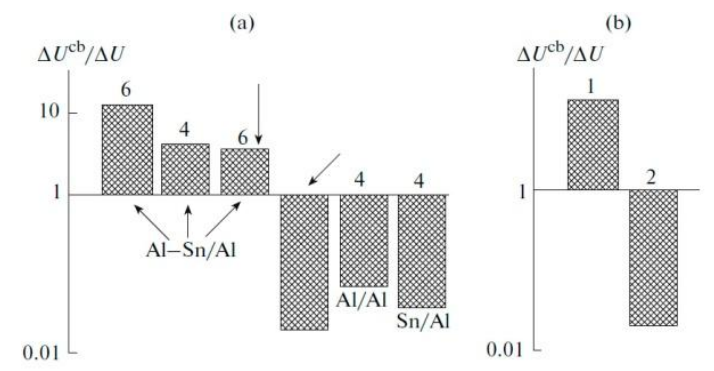

Fig. 5. Relative wear of the surfaces during the ESA in air (a) and the comparison of the surfaces' wear (b) during the treatment in air (1) and in an argon atmosphere (2) - the numbers in Fig. 5(a) correspond to the modes of the treatment of generator ALIER-31; upper arrows (a) shows testing results for surfaces after polishing $\left(\Delta \mathrm{U}^{\mathrm{cb}} / \Delta \mathrm{U}>1\right)$ and without $\operatorname{ESA}\left(\Delta \mathrm{U}^{\mathrm{cb}} / \Delta \mathrm{U}<1\right)$

parameter) was measured. These values for the different conditions of coating deposition are shown in Fig. 6, 7 (for ESA by automation).

The obtained results of the tests for surfaces, manufactured ESA by hand, are integrated in the diagrams of Fig. 5. As is seen, in contrast to be plating 
with Al-Sn alloy (i.e. in the conditions under which nanofibers of low-melted component of the TE are formed owning ESA) during $\mathrm{Al}$ and $\mathrm{Sn}$ TE plating at ESA, the wear resistance coatings cannot be manufacturing (Fig. 5).

In addition, it seems obvious that a crucial role in the observed effect of the extremely high degree of the counterbody wear made of hardened steel during its contact with the plated surface belongs to the formation not of tin nanofibers but rather of tin oxide nanofibers, since during the manufacturing of coatings in an argon atmosphere this effect is not observed (Fig. 5b, see also Fig. 2).

\subsection{Wear resistance of the coatings after ESA by the Al-Sn alloy. ESA by automation}

The machinig in conditions of ESA by automation take place in two variants [6]: mode I (the weight gain of the specimen under treatment) and mode II (method of surface modification without the weight gain, "sparking" of the surface). Results, presented on Fig. 4 and 6, shows that transition from mode I to mode II is accompanied: (1) the weight loss after the treatment for the both the specimen and the TE; (2) the decrease in the surface roughness.

Fig. 2 shows that nanofibers are also formed during the automatic coating process. In certain cases they are even of micrometric sizes (Fig. 2c, d). However, in this case (the formation of "thick" fibers) it is possible to determine their elemental composition more precisely (Fig. 2e). It is obvious that the stoichiometry of the fibers is such that the tin concentration is substantially higher than corresponding $\mathrm{SnO}_{2}$.

The evident reason for this phenomenon is pulling the tin fibers with oxidized surface out of the tin alloy melt under the action of an electric discharge. The fiber core is tin. It is apparent that the ratio of tin and the surface oxide in the fiber will depend on the both the size of the melted drop (i.e. the diameter of the

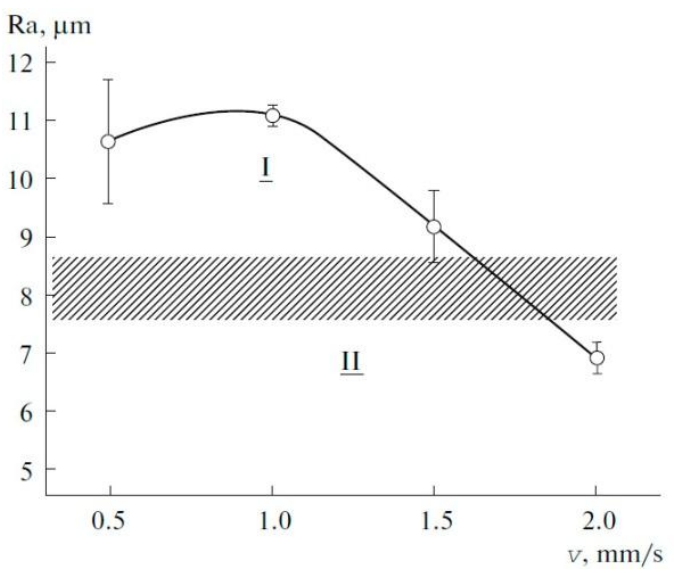

Fig. 6. $R a$ dependence on $\mathrm{TE}$ feed rate for method 2 treatment - ashed area is region of transition from mode I to "sparking" mode (mode II)

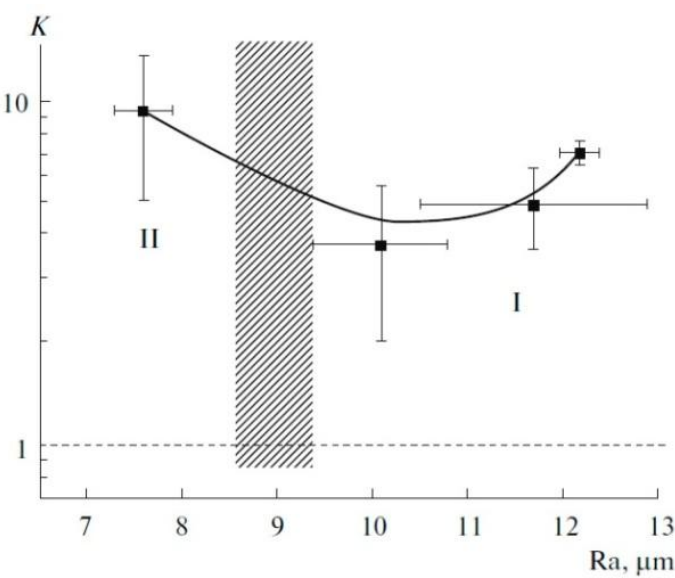

Fig. 7. Dependence of counterbody relative wear on surface roughness obtained after ESA at dry friction for surfaces treated under condition of constant energy supply into discharge gap during treatment (here: I and II - modes as in Fig. 3, 5)

forming fiber) and the modes of the electric treatment including the TE feed rates across the specimen. The change of the elemental composition of nano-(micro-) fibers should lead to the change of the surface properties.

As is follows from fig 7, the excessive wear of the counterbody relatively to the treated surfaces at dry friction is observed for the specimens obtained by method 2 in all cases (both mode I and mode II). For the surfaces manufacturing in the "sparking" mode the $K$ value is maximal, and the counterbody wear exceeds the wear of the ESA surface almost by an order of magnitude. For the method 1 (constant number of deposited layers) $K$ value depend from TE feed rate. At low TE feed rates $K>>1$. At TE feed rates $\sim 1$ and more $K \leq 1$.

The abnormal wear of counterbody from hardened steel at friction with nanostructuring surfaces, obtained by ESA TE from Al-Sn take place both at dry friction (Fig. 7) and lubrication friction (Fig. 8). In latest case $\mathrm{K}$ can be equally $\infty$ (Fig. 8). This means that material of the counterbody from hardened steel at friction "smeared" as a butter on a nanostructured surface, obtained by ESA.

Earlier it was shown that the observed effect of abnormal wear of the counterbody made of hardened steel that worked in the friction couple with the coatings under study (but manufactured in the manual mode), increases with the increase of the surface roughness $[3,5]$.

The results of this investigation could answer the question if the fact of high $R a$ values that are reached under the ESA is a necessary condition for the observed effects. The results presented in Fig. 7, 8 allow us to infer: a) under automatic deposition of the electrospark coatings (electrospark surface modification) the effect of abnormal wear of the hardened 


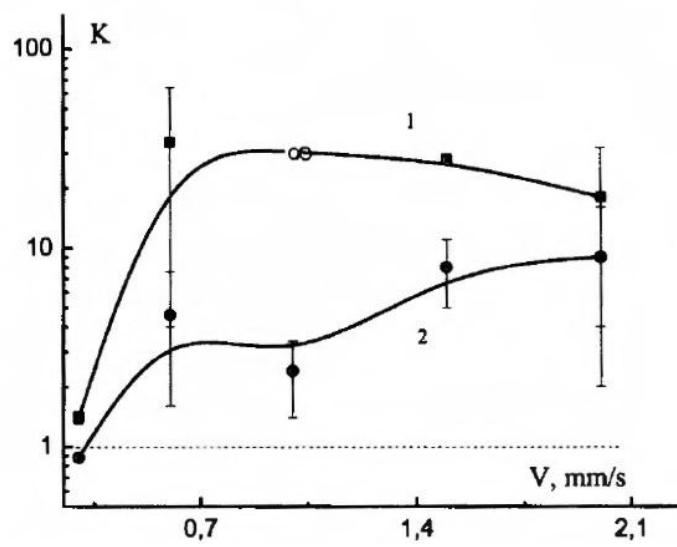

Fig. 8. The effect of the TE feed rate against surface treated on the value of a counterbody relative wear at lubricated friction with the ESA treated surfaces after the grindingin (1) and after two stages of testing (2)

steel counterbody is also observed (Fig 7, 8); b) the ESA surface roughness is insignificant for the abnormally high counterbody wear; c) this effect does not depend on whether the deposition of the layer occurs (i.e. the ESA itself, mode I) or the treatment leads to the weight lost of trated surface (at the "sparking" mode used) (Fig. 7); d) both at dry friction and a lubrication friction abnormal wear of counterbody from hardened steel take place in the friction couple with such surfaces.

\section{CONCLUSIONS}

Surfaces nanostructuring as the result of the ESA with TE made of the alloy containing the infusible matrix with an easily fusible component as a mechanical mixture have unique abrasive properties. Both at dry friction and a lubrication friction the excessive wear of the counterbody made of the hardened steel take place in the friction couple with such surfaces. Abnormal wear of countrbody at friction with these surfaces take place owing to the formation of $\mathrm{SnO}_{2}$ nano- (micro-)fibers at ESA with Al-Sn TE.

\section{Acknowledgements}

This research was funded by the Academy of Sciences of Moldova (project no. 11. 817.05.05A) and in part by the Technical University of Moldova and by the Pridnestrov'e Shevchenko State University.

\section{References}

1. Lazarenko B.R., Lazarenko N.I. (1964). Electrospark machining of metals. Consulting Bureau, New York. USA.

2. Gitlevich A.E., Mihailov V.V., Parkansky N.Y., Revuzky V.N. (1985). Electric spark alloying of metals surfaces. Stiintsa, Kishinev, USSR.
3. Dikusar A.I. (2011). Obtaining Nanowires under Conditions of Electrodischarge Treatment. In: Nanowires - implementations and applications, Abbas Hashim (Ed.), Intech, pp. 357-374.

4. Yurchenko V.I., Yurchenko E.V., Fomichev V.M., Baranov S.A., Dikusar A.I. (2009). Obtaining of nanowires in conditions of electrodischafge treatment with Al-Sn alloy, Surface Engineering and Applied Electrochemistry, Vol. 45, No. 4, pp. 259-264.

5. Agafii V.I., Yurchenko V.A., Yurchenko V.I., Fomichev V.M., Petrenko V.I., Dikusar A.I. (2011). Wear resistance of coatings manufacturing by electric spark plating with Al-Sn electrodes. Surface Engineering and Applied Electrochemistry, Vol. 47, No. 6, pp. 488-492.

6. Agafii V.I., Petrenko V.I., Fomichev V.I.,Yurchenko V.I., Yurchenko E.V., Dikusar A.I. (2011). Deposition of $\mathrm{Al}$-Sn coatings on aluminum surface using electrospark alloying and their wear resistance under dry friction. Surface Engineering and Applied Electrochemistry, Vol. 49, No. 3, pp. 181-188.

\section{Biographical notes}

E.V. Yurchenko, I.D. Rushika - biographies and photographs of the authors are not available.

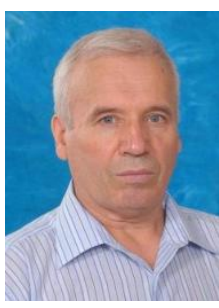

Vasile I. Agafii working in Academy of Sciences of Moldova's Institute of Applied Physics, where currently he is a senior scientific researcher in Laboratory of Electrophysical and Electrochemical Material Treatment Methods and in Shevchenko Pridnestrov'e State University. Dr. Agafii carry out a researches in area related with the electrochemistry and surface science, which focused on measurements and analyses of tribochemical properties, temperature stability, activation energy, microhardness and surface roughness.

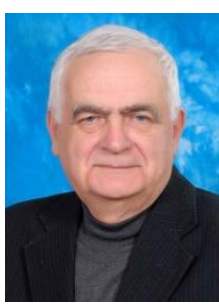

Alexandr I. Dikusar is corresponding member of Academy of Sciences of Moldova. Prof. Dikusar working in ASM's Institute of Applied Physics, where currently he is head of Laboratory of Electrophysical and Electrochemical Material Treatment Methods and in Shevchenko Pridnestrov'e State University. His research interests focuses on issues related with the electrochemistry and surface science, such as, e.g. electrodepostion, electrospark alloying, nanostructuring, corrosion. He is author of more than 190 scientific papers in various international and national journals, book chapters and conference proceedings. 